\title{
Entrevista
}

\section{Nuevas tecnologías, desde una visión antropológica}

DOI: 10.29236/sistemas.n154a4

Julio Ernesto Rojas, advierte que "ahora se crean sobre la marcha las reglas del juego y las tecnologías se han convertido en un aliado valioso para resolver problemas sociales, pero también para incrementar los índices de inequidad en el mundo".

\section{Sara Gallardo M.}

El antropólogo y doctor en Teoría de la Educación y Pedagogía Social, Julio Ernesto Rojas, con 20 años de docencia universitaria, diversos proyectos de investigación y varias publicaciones respondió algunos interrogantes sobre la sociedad 5.0 y el impacto de las nuevas tecnologías en curso.

Revista Sistemas: De cara a la sociedad 5.0, hay quienes afirman que se requiere una estructura mental para la construcción de sociedad. ¿Qué opina al respecto?
Julio Ernesto Rojas: Recuerdo que la primera vez que leí acerca del concepto sociedad 5.0, fue en el informe del quinto plan básico de Ciencia, Tecnología e Innovación japonés en 2015. Entiendo ese concepto radicalmente diferente al de industria 4.0, generado en Alemania y proyectado por USA; la transformación digital no es solamente un problema de máquinas y redes, sino de representación mental acerca de la relación entre humanos y no humanos en la construcción de una nueva representa- 
ción de mundo. El mundo oriental nunca ha diferenciado entre el adentro y el afuera como lo ha hecho el mundo occidental en donde hasta hace muy poco tiempo era absolutamente clara la posición entre el sujeto y el objeto (monismo vs dualismo).

Este hecho se puede constatar en casos como que, en el monismo oriental se vea a japoneses casándose con muñecas inflables o con software, y que, en el dualismo occidental, la mayoría de la gente crea que la globalización es un fenómeno independiente de su cotidianidad local, o que la tecnología digital es como una antigua llave de tubería, es decir "una herramienta objetivable, que tomas y dejas bajo tu control, o un objeto cuya relación siempre decides tú".

Sintetizando esta respuesta, efectivamente, en la nueva era en donde los sistemas de información y la inteligencia artificial son actores, no solamente protagónicos, sino de los cuales casi que tendremos una franca dependencia, nuestra representación mental acerca de lo social, lo colectivo y los actores que construyen representación de mundo, tendrá que cambiar radicalmente. Al respecto, Bruno Latour, junto con Michel Callon y John Law, propusieron en los años 80 la teoría del actor red, para alertarnos acerca de la necesidad de modificar la idea que tenemos de la relación entre actores humanos y no humanos, y como cada uno de ellos ac-

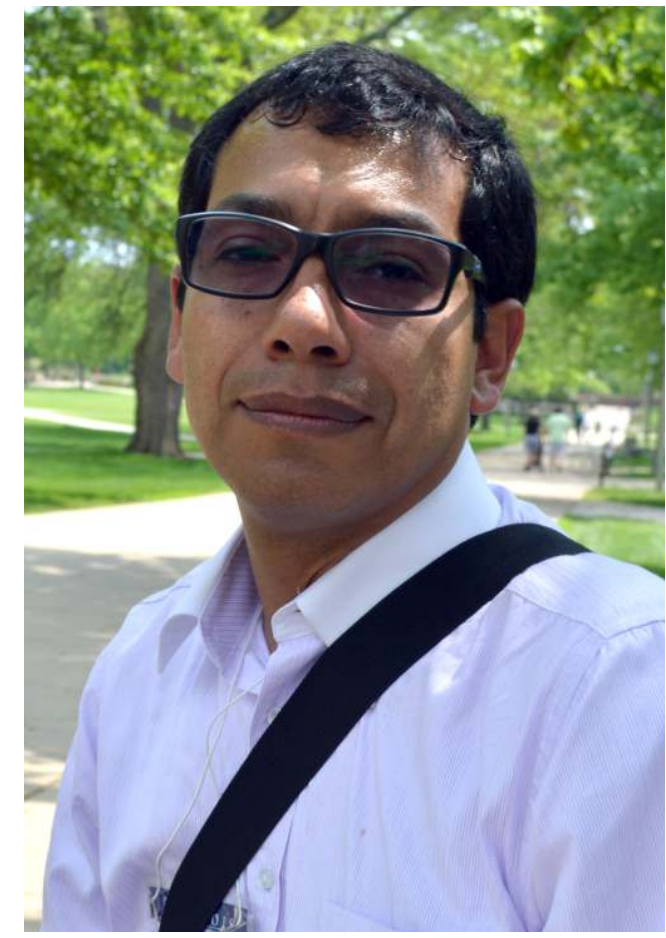

túa como determinante de aquello que conocemos como "lo social".

RS: También se dice que es necesario invertir en la apropiación de las tecnologías por parte de los ciudadanos, que no basta con disponer de las mismas. ¿Cómo ve este panorama en el país?

JER: Es absolutamente claro que vivimos en una época diferente a las anteriores. A propósito de la pregunta anterior, recuerdo el texto de Atlas de Michel Serres, en el que hace una brillante exposición de lo virtual, las máquinas y la representación de mundo que creamos los seres humanos. Por ejemplo, nuestra idea del tiempo y del espacio se ha venido modificando a lo largo de nuestra historia y la tecnología ha sido la protagonista principal de di- 
cha transformación, si tuviésemos que movilizarnos a pie o en bicicleta, difícilmente podríamos hablar de las cosas que hacemos ahora o de las relaciones que construimos en un mundo global (tuvo que aparecer el automóvil, el avión y la internet, entre otros).

El mundo construye una nueva representación de lo social y lo colectivo, en la que los sistemas de información, las redes digitales y la construcción de algoritmos de IA se ha convertido en una necesidad cotidiana para desarrollar actividades económicas, culturales, políticas y sociales de la vida contemporánea. En este nuevo diálogo, si queremos estar allí, esas tecnologías tienen nuevas características como que se actualizan de manera vertiginosa, no podemos durar con un tipo de tecnología para toda la vida como antaño lo hacíamos con la bicicleta, el automóvil o la radio.

\section{RS: Advierten los estudiosos del} tema que los ciudadanos deben tener claridad sobre los algoritmos y para lograrlo los ingenieros de sistemas juegan un papel fundamental. ¿En su concepto de qué manera debería ser esa contribución?

JER: Esta pregunta nos rebota nuevamente a la primera que realizó, es decir: el problema de entender qué significa sociedad 5.0. Pero es muy importante porque allí radica gran parte del problema del dualismo en la representación del mundo que tendremos que resolver especialmente en occidente.
Mientras que la metáfora de industria 4.0 significa una radical apuesta por la tecnología al servicio de la industria y específicamente al nuevo sistema económico, que nada tiene que ver con la revolución industrial de la modernidad, la metáfora de la sociedad 5.0 significa básicamente un nuevo contrato social, en el que las máquinas y los algoritmos se entienden como actores que agencian cambios en los colectivos sociales y con los cuales cada ciudadano debe tener competencias básicas para dialogar; un ciudadano dialogando con el algoritmo. En tal sentido, aunque el problema tiene una base fuerte en las facultades y escuelas de ingeniería de sistemas, va más allá incluso de la categoría de ingeniería de sistemas.

En el esquema japonés de sociedad 5.0 mencionado al comienzo, a esto se le denomina trabajo sobre las "tecnologías fundamentales" que significa que habrá que formar muchos profesionales altamente capacitados en robótica, tecnología de sensores, tecnología de actuador, biotecnología, tecnología de interfaz humana, nanotecnología y tecnología ligera. Cada una de las mencionadas involucra la necesidad de un diálogo inter y transdisciplinar. De hecho, las facultades de ingeniería no solo deberían esperar, sino presionar la transformación a nuevas categorías de programas de formación que corran su frontera disciplinar del conocimiento. 
RS: ¿Las empresas deben ser digitalmente responsables? ¿Cómo Io define?

JER: En este nuevo contrato social, todos debemos ser digitalmente responsables. En los primeros cuarenta años del desarrollo social de internet, las empresas recorrieron el espacio digital sin ningún tipo de límite o regla. Solamente hasta en la última década, los Estados y la sociedad civil se han puesto en la tarea de pensar seriamente el asunto. Cristóbal Cobo publicó un libro en 2019 relacionado con el tema, nos habla de la necesidad de actuar con pensamiento crítico acerca de si "aceptamos condiciones" cada vez que queramos acceder a un servicio o una oferta que propone una empresa en internet.

Es indispensable pensar de manera crítica sobre las implicaciones que tiene cada transacción social o económica realizada en internet. Es un tema que debería estar en cabeza del Estado a manera regulación y de la sociedad, a manera de formar consumidores informados y críticos de lo que implica cada transacción o servicio que acepta en internet.

Obviamente, ayudaría mucho que las empresas funcionaran de manera responsable, lo difícil es saber si podrán mantener una actitud de este tipo en un sistema económico que, a todas luces, se ha convertido en un campo de competitividad altamente compleja, en el cual cada mínima diferencia marca pérdidas o ganancias fundamentales para el ecosistema digital empresarial.

\section{RS: Existen opiniones relaciona-} das con la colonización de la vida humana ejercida por la tecnología. ¿Cuál es su mirada en este contexto?

JER: Las implicaciones son realmente interesantes. Desde el enfoque de industria 4.0 nos mantenemos en un paradigma dualista en el cual nosotros controlamos la máquina y decidimos en qué debe actuar y cómo debe hacerlo. No estamos preparando a nuestros profesionales para dialogar con ella, para establecer el nuevo contrato de lo colectivo, para que los humanos y los no humanos (en términos de Latour) emprendan un proyecto de sociedad.

Pareciera que los japoneses hace algún tiempo han resuelto ese tema. El concepto de sociedad 5.0 para ellos significa un plan de formación de los humanos para las tecnologías fundamentales en el futuro y especialmente de preparación para dialogar con la IA. De hecho, muchos científicos de las ciencias de la información y el trabajo con la IA lo sienten, se puede seguir el rastro de estas máquinas solo por poco tiempo; después la mente humana se pierde en la velocidad de procesamiento, la cantidad de información y el número de permutaciones que realiza la máquina, hasta que volvemos a conectarnos con el resultado social 
que esta nos ofrece, bien sea en algoritmos de rutas de transporte, manejo de la bolsa de valores, o predicciones de diferente tipo de procesos de producción agrícola o industrial.

\section{$R S$ : Se requiere una regulación de los derechos digitales para redis- tribuir la riqueza, contemplando la inequidad existente en la sociedad. Es necesario que las comunidades se reinventen para disminuir tal ine- quidad. ¿Está de acuerdo?}

JER: Este tema es aún más complejo, toda vez que está relacionado no sólo con las tecnologías digitales, sino especialmente con una forma de reinvención que viene desarrollando el sistema económico. La economía de servicios que se viene promocionando en los últimos 50 años, tiene que ver con la desaparición del contrato social moderno, el contrato de la revolución industrial. Ahora se crean sobre la marcha las reglas del juego y las tecnologías se han convertido en un aliado valioso para resolver problemas sociales, pero también para incrementar los índices de inequidad en el mundo.

El profesor Joseph Stiglitz plantea que la inequidad actual es consecuencia del fracaso de los sistemas políticos liberales y frente a las promesas incumplidas que han debilitado todo el sistema político, las organizaciones han entrado a jugar un papel de desequilibrio importante, valiéndose especialmente de la apropiación de las tecnologías digitales, generando un sistema en el que se privilegian y prevalecen los intereses de las más grandes empresas. Esto es algo absolutamente catastrófico porque se juega a lo que el profesor Branko Milanovic, la regla de "el ganador toma todo". El profesor Stiglitz propone la realización de un nuevo contrato social que proponga un equilibrio entre el estado, el mercado y la sociedad. En dicho contexto las tecnologías digitales y su regulación se pueden convertir en los mejores aliados para la construcción de prosperidad en nuestras sociedades.

Sara Gallardo M. Periodista comunicadora, universidad Jorge Tadeo Lozano. Ha sido directora de las revistas Uno y Cero, Gestión empresarial y Acuc Noticias. Editora de Aló Computadores del diario El Tiempo. Redactora en las revistas Cambio 16, Cambio y Clase Empresarial. Coautora del libro "Lo que cuesta el abuso del poder". Ha sido corresponsal de la revista Infochannel de México; de los diarios La Prensa de Panamá y La Prensa Gráfica de El Salvador y corresponsal de la revista IN de Lanchile e investigadora en publicaciones culturales. Se ha desempeñado también como gerente de Comunicaciones y Servicio al Comensal en Inmaculada Guadalupe y amigos en Cía. S.A. (Andrés Carne de Res) y editora de Alfaomega Colombiana S.A.; es editora de esta revista. 